\title{
Rádio e memória do cotidiano ${ }^{1}$
}

\author{
Nelia Del BIANCO ${ }^{2}$
}

Resumo:

A partir da compreensão que a memória é uma construção social , produzida pelos homens em suas relações sociais e experiências vividas (HALBWACHS, 2013), o artigo aborda como o rádio participa da vida cotidiana e colabora para a construção de sentidos na interação entre ouvintes e comunicadores, por meio da análise de conteúdo de comentários dos ouvintes de quatro emissoras populares brasileira registrados em fanpages no Facebook. Os comentários revelam histórias de vida tecidas nas relações de afeto, amizade entre ouvintes e o espaço radiofônico. Constata que a reiteração dessa prática comunicacional é parte da construção de laços sociais, sentimento de pertencimento e de coesão garantida pelos quadros sociais da memória coletiva. É um vínculo que se estabelece a partir da tradição da cultura oral que tem sido capaz de suscitar efeitos mesmo em tempos de Internet móvel e a interação das redes sociais.

Palavras-chave:

Mídia. Memória coletiva. Rádio. Comunicador popular.

\section{Radio and everyday memory}

\begin{abstract}
:
From the understanding that memory is a social construct, produced by men in their social relations and lived experiences (HALBWACHS, 2013), the article discusses how radio participates in everyday life and collaborates to construct meanings in the interaction between listeners and communicators, through the content analysis of comments from listeners of four Brazilian popular broadcasters registered in fanpageson Facebook. The comments reveal stories of life woven in the relationships of affection, friendship between listeners and radio space. It notes that the reiteration of this communication practice is part of the construction of social bonds, a feeling of belonging and cohesion guaranteed by the social frameworks of collective memory. It is a link that establishes itself from tradition of oral culture that has been able to elicit effects even in times of mobile Internet and the interaction of social networks.
\end{abstract}

Keywords:

Media. Collective memory. Radio. Popular speaker.

\section{Radio y memoria del cotidiano}

\author{
Resumen: \\ A partir de lacomprensión que la memoria es una construcción social, producida por loshombresen sus \\ relaciones sociales y experiencias vividas (HALBWACHS, 2013), el artículo aborda cómola radio \\ participa de la vida cotidiana y colabora para laconstrucción de sentidos enlainteracción entre oyentes y \\ comunicadores por intermédio delanalisis de contenido de losoyentes de cuatro estaciones populares \\ brasileñas registrados en fanpages enel Facebook. Los comentariosrevelanhistorias de vida tejidasenlas \\ relaciones de afecto, amistad entre oyentes y elespacio radiofónico. Constata que lareiteración de esta \\ práctica comunicacional es parte de laconstrucción de lazossociales, sentimiento de pertenencia y de \\ cohesióngarantizada por loscuadrossociales de la memoria colectiva. Es un vínculo que se establece a

\footnotetext{
${ }^{1}$ Versão inicial do artigo foiapresentada no XI Encontro Nacional de História da Mídia, ocorrido entre 8 e 10 de junho de 2017, naUniversidade Presbiteriana Mackenzie, em São Paulo.

${ }^{2}$ Doutora em Comunicação pela Universidade de São Paulo (USP), comestágio de pós-

doutoradonaUniversidade de Sevilha. Professora dos Programas de Pós-Graduação em Comunicação da Universidade de Brasília (UnB) e Universidade Federal de Goiás (UFG). Pesquisadora Colaboradora Plena da UNB.E-mail: nbianco@uol.com.br
} 
partir de latradición de la cultura oral que ha sido capaz de suscitar efectos incluso entiempos de Internet móvil y lainteracción de las redes sociales.

Palabras clave:

Medios. Memoria colectiva. Radio. Comunicador popular.

\section{Introdução}

A constatação da onipresença da mídia no cotidiano como uma dimensão essencial da vida e parte da "textura geral da experiência humana" (SILVERSTONE, 2002, p.14) é o ponto de partida para a análise das manifestações de ouvintes de rádio em fanpages de emissoras populares no Brasil no Facebook com o propósito de identificar marcas da memória afetiva em relação ao meio. Como espaço de entretenimento, conhecimento e informação sobre o que acontece no mundo, o rádio propicia à audiência uma experiência social subjetiva de acolhimento, proximidade, intimidade e conexão com seu entorno de forma peculiar.

A especificidade dessa relação está na capacidade do rádio afetar as pessoas profundamente, "oferecendo um mundo de comunicação não expressa entre o escritorlocutor e o ouvinte" (MCLUHAN, 2000, p. 336). Essa conexão íntima é estabelecida graças ao poder da linguagem que, por meio do som, propicia a construção de imagens

sonoras, ativando o imaginário da audiência. É na unisensorialidade que reside o eixo da intimidade, segundo Bachelard (1986, p.173) ao apontar o rádio como a "realização cotidiana da psique humana".

$\mathrm{Na}$ era eletrônica, segundo McLuhan (2000), o rádio trouxe à tona ecos de antigos tambores tribais. Resgatou, pela força de seu conteúdo tecnológico, o vínculo entre pessoas em sua comunidade. Essa natureza descentralizada e pluralística, ao mesmo tempo coletiva e pessoal, atua no sentido contrário à homogeneização. Como identificou o ensaísta canadense, o meio ressuscita arcaísmos e a revivência do poder da identidade. O sentido de coletivismo tribal está baseado na evidente integração do rádio ao cotidiano das pessoas, onde, muitas vezes, a audição acontece associada às tarefas realizadas em diferentes lugares e situações. O vínculo social que estabelece com o modo de vida envolve o compartilhamento de patrimônios comuns como a língua, a música, o trabalho, os esportes, as festas, a amizade entre pessoas que partilham o gosto por determinados programas. É um espaço de reconhecimento de ouvintes como pertencentes à dinâmica cultural da cidade, bairro ou comunidade, tornando-os mais próximos e semelhantes. 
Ao fazer parte da fonosfera que impregna a vida, o rádio colabora na construção de significados por meio dos processos de mediação. Essa mediação implica num movimento de circulação de significados que vão além dos limites textuais ou visuais para oferecer descrições da realidade. Desse modo, a mediação é infinita, "produto do desenredamento textual nas palavras, nos atos e nas experiências da vida cotidiana" (SILVERSTONE, 2002, p. 37).

Os significados mediados movem-se através do espaço e do tempo, fixam-se na memória como experiência vivida constituída por diversos sentidos culturais como lúdico, afetivo, solidário, reconhecimento, amizade, sentimentos, gostos, percepções, visões particulares de mundo e até mesmo a questões existenciais da audiência. A memória dessa experiência vivida tem uma dimensão individual que se integra à memória coletiva, entendida como aquela que compreende todas as reminiscências em comum que pertencem aos membros de um determinado grupo social (HALBWACHS, 2013, p. 45). Neste artigo, entende-se que os ouvintes de emissoras populares são sujeitos sociais que partilham de uma experiência comum de convivência diária com comunicadores radiofônicos tecida por laços de proximidade a ponto de se identificarem como membros de uma família.

É, portanto, no processo de interação social que acontece a formação da memória coletiva, cujo conteúdo é capaz de representar o conjunto de membros que a construiu. Mas, o fato de estar incluso em uma coletividade não cessa o aparecimento da individualidade dos componentes: [...] a memória coletiva tira sua força e sua duração do fato de ter por suporte um conjunto de homens, não obstante eles são indivíduos que se lembram, enquanto membros do grupo. (HALBWACHS, 2013, p. 51).

Embora a relação da sociedade com os artefatos comunicacionais tenha se modificado substancialmente na passagem da era eletrônica para a comunicação digital em rede, especialmente com a ascensão da Internet móvel, é possível verificar nas mensagens de ouvintes expressas em fanpages $^{3}$ de rádios populares que esse vínculo tribal com o arcaísmo da cultura da oralidade não se desfez.

Foram analisados comentários de ouvintes publicados de 2015 a 2017 nas fanpages no Facebook das emissoras Super Rádio Tupi, do Rio de Janeiro; Rádio Globo, do Rio de Janeiro; Verdes Mares, do Ceará; e Capital 1.040, de São Paulo. São comentários espontâneos que registram opinião sobre o que pensam a respeito da rádio, dos comunicadores e os sentidos gerados nessa convivência cotidiana.

\footnotetext{
${ }^{3}$ No Facebook, a fanpagedifere de uma conta comum e pessoal, por ser umespaço que reúne fãsaoinvés de amigos. Para umaemissora de rádio, a fanpagetem sido umespaço de formação de comunidades de ouvintes que aceitamseusprincípios e estratégia editorial.
} 
Utilizou-se a análise de conteúdo para extrair significação do texto. Para tanto, adotou-se a perspectiva de Laville e Dionne (1999, p. 214), que entendem a análise de conteúdo como uma metodologia para desmontar a estrutura e os elementos do conteúdo para esclarecer suas diferentes características e extrair sua significação. Seguindo os passos de Bardin (2009, p. 121), foi realizada inicialmente uma pré-análise, envolvendo a leitura do total de comentários registrados no período 2015-2017. Foram identificados 680 de comentários postados nas páginas das quatro emissoras. A partir de unidades amostrais com as palavras-chave memória, saudade, família, recordação, aprendizado e vivência, foram selecionados 65 comentários para serem analisados. A amostra serviu também para formulação de hipóteses visando a elaboração de indicadores para a interpretação final. Na etapa seguinte, fez-se a exploração dos 65 comentários com o propósito de interpretá-los. A análise apresentada tem como pressuposto que os ouvintes são sujeitos sociais que dão sentido e significado ao que ouvem, assim como participam de uma cosmovisão compartida com o conjunto da audiência de cada emissora, constituindo uma comunidade de interpretação da experiência cotidiana de audição de rádio.

\section{Memória do rádio no contexto da convergência}

Os textos analisados emergem do contexto de rádios populares tradicionais. A rádio Verde Mares, está presente no cotidiano dos cearenses há mais de 60 anos, levando notícias, cultura, informação de utilidade pública e entretenimento. Destaca-se pela programação focada em jornalismo e esporte e pela afinidade que conquistou junto aos segmentos de classe social C e D. Vinculada ao grupo Diários Associados, a Super Rádio Tupi, do Rio de Janeiro, está no ar desde 1935 com programas estilo talk show,sob a liderança de comunicadores que fazem discussões diárias sobre problemas do cotidiano. A Capital 1040tem em sua programação um dos campeões de audiência do rádio AM em São Paulo, o comunicador ${ }^{4}$ Eli Corrêa. Em funcionamento desde 1978, a Capital se define como emissora popular com responsabilidade social que respeita o ouvinte e defende a cidadania. Criada há mais de 70 anos, a rádio Globo, do Rio de Janeiro, integra o Sistema Globo de Rádio com uma programação popular que mescla jornalismo, esporte e música. Teve em seus quadros comunicadores populares importantes, como Haroldo de Andrade,

\footnotetext{
${ }^{4}$ Entende-se por comunicador radiofônico“figura central da programação de emissoras de rádio em que predomina a transmissãoao vivo. É o responsável pelo diálogo imaginário - e comdose significativa de coloquialidade - estabelecido pela estação de rádiocom o ouvinte [...] No rádiopopular, apresenta-se comoumcompanheiro, a voz do radinho de pilha, lado a lado com a dona-de-casa, o motorista de táxiou o idososolitário" (FERRARETTO, 2010, p. 312-3).
} 
e narradores esportivos, a exemplo de Osmar Santos. Em 2017, a emissora modificou substancialmente a programação, substituindo parte dos antigos comunicadores por personalidades da TV detentoras de milhares de fãs e seguidores nas redes sociais.

Embora sejam tradicionais, as emissoras analisadas possuem site e utilizam as redes sociais para enfrentar o desafio de encontrar para si um novo espaço num ecossistema midiático em rede cada vez mais multiplataforma e em constante mutação. $\mathrm{O}$ comunicador continua a ser uma figura pivot na estratégia de comunicação dessas emissoras populares pela força discursiva e relação empática que consegue estabelecer com a audiência. No entanto, do ponto de vista do público, os tradicionais modos de escuta e fruição têm se alterado frente à multiplicidade de oferta de conteúdos em mídias digitais.

No Brasil, o rádio alcança $89 \%$ da população residente nas principais regiões metropolitanas, o equivalente a 52 milhões de pessoas. Em média, as pessoas passam 4h36 sintonizados diariamente em alguma emissora, o que representa cerca de $20 \%$ do seu dia, segundo pesquisa Kantar IBOPE Media de 2017. A audiência doméstica ainda é predominante $(58 \%)$, porém, não se pode desconhecer a velocidade do crescimento da escuta por meio de dispositivos móveis (14\%) e pelo computador (4\%).

A permanência do rádio atual é baseada na tradição: centralidade da emissão ao vivo, ciclo de 24 horas por sete dias, sinal de horário marcando a temporalidade linear cotidiana. No entanto, o rádio vem sendo usado cada vez mais como ruído de fundo, para uma audiência desatenta, dividida entre acessar Internet pelo celular e realizar outras atividades simultaneamente. Significa dizer que a temporalidade linear do rádio convive com o tempo assíncrono, especialmente quando a escuta se dá por dispositivos móveis ou no computador. O consumo no multi-contexto (móvel ou não, online ou não) comprova a conhecida flexibilidade do rádio em se adaptar a diferentes suportes digitais. A sua permanência no ecossistema midiático reside na capacidade de absorver novas tecnologias para oferecer conteúdos sonoros em linguagem hipertextual e interativa, proporcionando ao público experiências diferenciadas. É a soma perfeita da imensa flexibilidade e da relevância do conteúdo de proximidade que mantém a identificação da audiência com o rádio, mesmo numa era de superabundância comunicacional.

\section{Memória afetiva familiar}


A análise apresentada parte do entendimento que o ouvinte é um sujeito social ativo integrante de um grupo que partilha do mesmo hábito de ouvir determinada emissora. O habito se forma no espaço da convivência familiar no qual os pais atribuíam ao meio significado que transcendia a relação utilitária de marcador do tempo, por exemplo. Nos comentários, a expressão da memória de um tempo que gostariam de eternizar.

A rádio me acordava na infância. E hoje é minha companheira. Minha mãe programava o rádio para despertar na Capital. Hoje sou eu quem faço. Não tenho vizinhos e amigos onde moro. Mas tenho sempre um amigo na Capital. (ADRIANA, 16 maio 2016).

Hoje estou com 35 anos de idade e comecei a recordar da época que eu era criança onde minha mãe ouvia todos os dias a rádio Capital. Hoje baixei o aplicativo de rádio no meu celular e matei a saudade de ouvir Eli Corrêa apresentando o quadro "Que saudades de você". Confesso que me emocionei muito, foi muito bom matar a saudade. (REINALDO, 20 abr. 2016).

Para Halbwachs (2013, p. 32), o indivíduo que lembra é sempre uma pessoa inserida e habitada por grupos de referência. A memória é sempre construída em grupo, mas também é um trabalho do sujeito. As memórias individuais correspondem ao acúmulo de lembranças exclusivas pertencentes a cada indivíduo. No entanto, a convivência do sujeito em sociedade não o exime de elaborar lembranças pessoais. De acordo com Halbwachs (2013, p. 54), as duas memórias se interdependem constantemente, ou seja, a individual apoia-se na coletiva para precisar alguns dados, assim considerando que "um homem para evocar seu próprio passado, tem frequentemente de fazer apelo às lembranças dos outros”.

No caso dos ouvintes, o grupo de referência é a família, cujo papel foi o da introjeção do hábito de escuta como marcador das atividades cotidianas - do despertar até o momento de dormir - que se mantém na memória como o local de aconchego. Ou seja, mesmo na vida adulta, esses ouvintes mantêm a audiência de rádios da infância para reavivar a memória desse afeto.

Na visão de Halbwachs (2013), a memória não tem passado, sobrevive enquanto seus personagens vivem ou se lembram. Portanto, não é algo pronto e acabado, cristalizado, e ganha atualidade à medida em que se vive cotidianamente a experiência de audição, como se pode denotar do comentário de Denise: 
É a minha rádio do coração [Capital], a toda hora e em todos os momentos da minha vida vocês fazem parte dos melhores e piores momentos da minha história. (DENISE, 21 dez. 2017).

A memória dos ouvintes expressa nos comentários pode ser entendida como ponto de convergência de diferentes influências sociais, em particular dos comunicadores, como uma forma particular de sua articulação para criar um sentido próprio, como se observa no comentário de Genivaldo:

Eu sou apaixonado por rádio desde os meus 10 anos e sempre gostei da rádio Verdes Mares. Estou há 42 anos ouvindo... Não dá pra falar dos grandes profissionais, todos tem uma história, uma biografia que a sente não vê por aí. (GENIVALDO, 06 jul. 2016).

Aqui vale salientar Pollak (1992), que vincula memória à identidade, sendo que esta se estabelece acerca de três elementos fundamentais: o lugar, o tempo e a percepção de coerência dos elementos que formam o indivíduo. Ou seja, a identidade liga-se, em essência, à memória, seja ela um dado histórico datado e socialmente estabelecido, portanto, sempre dinâmica e aberta. Quando ouvem programas tradicionais que estão no ar há mais de 30 anos, a memória da infância e adolescência é reavivada no tempo presente.

Bom dia! Adoro a programação da rádio Capital. Faz eu lembrar muito da minha mãe. Ouço o Eli Correa desde pequena. Adoro!!! (HELIANA, 29 jul. 2017).

Eu acho uma maravilha a verdinha, amiga que me acompanha já desde a minha adolescência e agora já é uma jovem adulta. (REGIANE, 26 ago. 2016).

Essa rádio [Verdes Mares] está no meu coração desde criança. Quando morava em Fortaleza eu ouvia todas as manhã antes de ir para o colégio. Saudades. Programa Paulo Oliveira, João Inácio Junior... (ELIEL, 03 jul. 2015).

Na memória dos ouvintes, a família é o espaço de aprendizado da escuta e da construção de uma relação afetiva que perdura por toda a vida. No entanto, acontece um fenômeno de transferência dessa noção de família para a emissora. Alguns ouvintes identificam a rádio como uma espécie de família imaginária e seus profissionais, como pessoas próximas. O sentido de pertencimento a essa família gera laços de intimidade e de confiança. Em momentos de dificuldades alguns ouvintes expõem seus problemas, 
na crença de que poderão ter apoio e encontrar solução junto à família radiofônica, como se observa nesses comentários:

Bom dia amigos da super família Tupi. Eu venho através dessa pedir ajuda de todos os amigos que tiverem informações de um Sandero Vermelho placa PWY 6689. Eu peço ajuda de todos pois o carro foi roubado é o meu ganha pão de todos dias. (MARCIA, 18 ago. 2017).

Bom dia família Tupi! Venho pedir encarecidamente uma ajuda a todos vocês. Que me ajude a arrumar um emprego. Estou desempregada, moro de aluguel não tenho como fazer para pagar minha compra de alimento. A conta de luz já está vencendo só preciso de um trabalho. Eu sou doméstica, faço faxina, tenho 42 anos e referências. Por favor me ajudem... (ARLETE, 25 abr. 2015).

O sentimento de pertencimento é a crença subjetiva numa origem comum que une distintos indivíduos. As pessoas pensam em si mesmos como membros de uma coletividade na qual expressam valores, medos e aspirações. Esse sentimento de pertencimento tem relação com a noção de participação. Na medida em que o ouvinte tem espaço para se expressar, sente-se ator da ação em curso, parte do processo de comunicação radiofônica. O rádio é de tal forma presente na vida que assume outros papéis: de amigo, de companheiro, de companhia:

Adoro a rádio Capital. Esta rádio é a minha verdadeira amiga. Ouço a rádio de manhã, tarde, noite e de madrugada. O meu rádio não conhece outra emissora. (SUSETE, 28 mar. 2016).

A verdinha faz parte da minha vida. Acordo e já ligo na verdinha. Essa rádio é mil. (GLORIA, 06 maio 2017).

Sem sombra de dúvida melhor rádio [Capital] para se ouvir. Parece que estão todos reunidos na nossa casa, muito a vontade, batendo papo, trazendo música, informações, alegrias, emoções, enfim rádio super gostosa de ouvir. (LURDES, 15 ago. 2017).

O pesquisador inglês Richard Hoggart （1987a), ao estudar a influência da cultura disseminada em meio à classe operária pelos meios de comunicação de massa , foi taxativo: a tradição oral mantém sua força na vida cotidiana. O interesse pelo rádio, o engajamento da audiência se dá pelo fascínio por histórias humanas. Interesse por tudo que é pessoal e íntimo, pela vida dos outros, pelo que é emocionante e facilmente 
compreensível, seja pelo local ou pelas pessoas (HOGGART, 1987b, p. 44). O autor entende que:

[...] os membros das classes trabalhadoras não tem sequer consciência do verdadeiro significado dessas influências, que se exprimem normalmente sob forma de um apelo ao companheirismo, por muito lato e centralizado que este seja, [...] A maioria reage favoravelmente a um apelo desse tipo, na medida em que este pode, até certo ponto, ser identificado com algumas atitudes antigas muito características. (HOGGART, 1987b, p. 257).

\section{Vínculo pessoal com os comunicadores}

São os comunicadores a figura pivot que cria laços de identificação com a audiência. $\mathrm{O}$ discurso desses profissionais é marcado pela busca da proximidade e intimidade. O comunicador transforma tudo o que diz no rádio em "seu, sua, é para você". Mais do que se dirigir aos ouvintes de forma íntima e pessoal, eles transformam uma audiência de anônimos em pessoas conhecidas, que partilham a mesma experiência cotidiana. Um aspecto dessa comunicação que mereceu críticas de Hoggart:

[...] esses amigos do público oferecem-lhe, na nossa época gregária, uma sensação de integração no grupo que é inteiramente falsa: seria preferível que as pessoas continuassem a sentir-se anônimas, pelo menos talvez tomassem a inciativa de tentar remediar de tal estado de coisas. (HOGGART, 1987b, p. 46).

No entanto, não se pode menosprezar a técnica da personalização e a força desse movimento para tornar ouvintes integrantes da família radiofônica. Sem dúvida, os comunicadores colaboram para o reconhecimento e identificação entre pessoas que habitam o mesmo local, ou vivem e partilham um modo de vida e uma cultura em comum.

Embora eu seja de São Paulo, um dos comunicadores que eu sempre acompanhei no rádio é o Antônio Carlos lá do Rio de Janeiro. Ouço seu programa desde criança devido ao meu avô e meu pai que são ouvintes por anos sempre começando às 6 da manhã. Alegre, simpático e irreverente e com cerca de 40 anos de rádio onde alegra as manhã dos brasileiros, deixou a rádio Globo no mês passado após 35 anos de emissora para se integrar a equipe da Super Rádio Tupi. Muito legal ver como ainda há emissoras que se importam em manter o bom e velho rádio popular. (LUIZ, 26 maio 2017).

Atualmente, o rádio popular tradicional está passando por um processo de 
reposicionamento da marca para se inserir no ambiente da convergência midiática e a transição do AM para o FM. A tendência das rádios tradicionais, na sua maioria AM, como as que fazem parte do escopo da investigação, é renovar conteúdos, programação e modernizar a imagem. A Rádio Globo optou por uma ação radical de reposicionamento e substituiu a maioria dos seus comunicadores tradicionais - a exemplo de Antônio Carlos, citado no comentário de Luiz - por apresentadores mais jovens, afinados com as redes sociais. O único a permanecer na nova programação da Rádio Globo foi Canázio, que passou a apresentar, aos domingos, o Revista Rádio Globo, em que os destaques da semana no país e no mundo são passados a limpo. A audiência reclamou da mudança de rumos:

\begin{abstract}
Eu nunca me prendi a rádio e sim ao comunicador. Tenho os meus prediletos e os acompanho para a rádio que for. Um deles é o Roberto Canázio, independente da rádio que for irei ouvi-lo. Há muito tempo ouço que o rádio iria acabar, não entendia porque. Hoje começo a entender. As pessoas que estão administrando as rádios parecem que estão com esse intuito. Estão trocando a rádio falada que é o que nós cariocas gostamos por mais músicas que é bem mais o estilo paulista. Não entendem que quem quer ouvir música vai para o YouTube, coloca $\mathrm{CD}$, existem mil jeitos de faze-lo. Se eu ligo uma rádio é porque quero ouvir os comunicadores, notícias, conversas, pois é assim que trabalhamos, não precisamos ficar parados para vê-los. Ficamos informados sem nos desviar dos nossos objetivos do dia a dia. Que pena, muito triste ver que aos poucos estão acabando com nossa diversão. Minha última opção é o Canázio, se ele sair desligarei meu rádio. (ROSI, 30 maio 2017).
\end{abstract}

Não entendo como vocês da alta cúpula da rádio [Globo] decidem sem consultar os ouvintes mudar de maneira intempestiva a programação. Tirar o Antônio Carlos e colocar o Otaviano Costa é no mínimo um tiro no pé. (ROSANGELA, 01 jun. 2017).

\begin{abstract}
Minha Rádio Globo está morta. Meus amores aprendam uma coisa. Nós, os jovens, estamos na Internet, estamos ouvindo música no YouTube, no Spotify, no iTunes. Quem ouve rádio é a galera mais antiga. Essa galera quer Antônio Carlos, Padre Marcelo Rossi, Roberto Canázio, não quer ouvir música da Anitta não amor. Querem fazer uma programação mais jovem, façam em outra rádio. O troféu burrice do ano vai para a Rádio Globo. Minha mãe já faz parte do movimento \#Partiu Tupi e que as vezes ouço junto com ela, apoio. (KARINE, 03 jun. 2017).
\end{abstract}

Os comentários mostram o apego de parte da audiência ao rádio falado tradicional, próximo, amigo, divertido, que faz companhia e estabelece conexões com a memória afetiva. O que está em jogo na atualidade é a transição entre o modelo linear massivo centrado na figura do comunicador para uma comunicação em rede, em que as 
ferramentas interativas da web 2.0 propiciam e amplificam as trocas sociais e o fluxo das informações.

A Internet é central nesse modelo de comunicação em rede (CARDOSO, 2007) ao propiciar conexões multidirecionais e ampla interatividade. É nesse contexto que estão inseridas as redes sociais, segundo Cardoso, oferecendo oportunidade para uma participação ativa da sociedade nasmúltiplas etapas de constituição dos processos comunicativos. Mais do que participar, é parte constitutiva do processo de circulação e distribuição de conteúdo por meio de ações de compartilhamento. Há uma descentralização das narrativas e discursos, antes monopolizados pela mídia de massa, o que induz a colaboração e a livre circulação de conhecimento. Coloca-se em destaque um novo paradigma a partir de uma outra lógica social: a comunicação compartilhada. Pessoal e participativa, ela rompe a verticalidade da informação. Devolve o papel de interlocução. Como lembra Cardoso (2007), a mídia já não é a mensagem, como pensava McLuhan e, sim, as pessoas são as mensagens, na era da convergência.

\section{Sentido de permanência}

Imerso num ecossistema midiático em rede, o rádio terá cada vez mais conteúdos organizados, sob demanda, disponíveis em aplicativos para celular, e no uso intensivo das redes sociais para interagir com a audiência. É um cenário particularmente interessante e desafiador, porque o rádio terá que superar o espectro das ondas eletromagnéticas para oferecer conteúdos em múltiplas plataformas e em diferentes formatos que atendam aos interesses da audiência, o que poderá permitir maior acessibilidade e ampliar o sentido de permanência.

A sua integração à Internet, aos dispositivos móveis, esgarça a demarcação de fronteiras, anteriormente claras, nítidas, do lugar que o rádio ocupava na mente da audiência. No ambiente da comunicação em rede, as fronteiras parecem difusas, sob múltiplas possibilidades de influências e interações em várias direções e sentidos. Ainda é possível verificar que permanece a relação de proximidade e de interação informal, porém, num ecossistema midiático que é oposto à tradição do tempo linear do rádio. $\mathrm{O}$ ouvinte coexiste com múltiplos tempos, fragmentação e segmentação de conteúdo. O hábito de escuta está inserido na cultura visual, no ambiente de multi-telas. Para sobreviver, o rádio precisa encontrar a sua tela no celular. Como ferramenta ubíqua, o celular é a principal porta de entrada para conteúdo e conectividade, incluindo práticas 
propagáveis de compartilhamento, em parte por ser rápido, manejável e útil. O celular hoje está integrado ao cotidiano, com implicações vastas e diferenciadas. Seu uso expande progressivamente para uma presença de quase dependência à totalidade das atividades de comunicação, ou seja, engloba ações de comunicação, informação e modos de expressão. Trata-se de uma nova fronteira comunicacional que expande a compreensão do mundo, produzindo novas subjetividades.

Nesse contexto, a tendência é vivenciar mudanças significativa no modo de fruição do rádio. Na memória afetiva ainda presente em parte da audiência, o meio se vincula à vivência familiar que regula as atividades cotidianas, uma espécie de marcador temporal que informa, diverte, anima e faz companhia. Diante do avanço da comunicação em rede, das novas mídias digitais e, em particular, a Internet móvel, emerge um sujeito múltiplo, descentralizado e com disposição para disseminar conteúdos que lhe agradam em grupos e comunidades constituídas em torno de interesses comuns. As práticas dos agentes sociais na sociedade em rede combinam diferentes meios na tentativa de obter resultados. O uso não é mais isolado, o rádio não é mais uma tecnologia isolada, mas é objeto de apropriação social que se faz de modos diversificados e combinados.

Nesse ambiente de convergência, o rádio terá o papel de reconhecimento e identificação entre pessoas que habitam o mesmo local, vivem e partilham um modo de vida em comum, interesses e gostos. Condição que desafia o meio em razão das suas características de flexibilidade e mobilidade. Para se fazer presente no cotidiano, terá de colocar a interação como central no seu modelo de comunicação. Interação que não será mais centrada no próprio meio, mas mediado pela Internet fixa e móvel. Inserido na convergência, passará a ser mais um elemento integrante da comunicação em rede, em que sua capacidade de afetar as pessoas individualmente se fundirá com a comunicação interpessoal da Internet e do celular, ligando audiências e emissoras sob uma matriz em rede, oferecendo aos seus utilizadores novas mediações e novos papéis ainda não dimensionados.

\section{Referências}

BACHELARD, Gaston. Devaneio e rádio. In: O direito de sonhar. São Paulo: Difel, 1986, p.176-181. 
BARDIN, Laurence. Análise de conteúdo. Lisboa: Edições 70, 2009.

CARDOSO, Gustavo. A mídia na sociedade em rede: filtros, vitrines, notícias. Rio de Janeiro: Editora FGV, 2007.

FERRARETTO, Luiz. Comunicador radiofônico [verbete]. Enciclopédia INTERCOM de Comunicação. v. 1, Dicionário brasileiro do conhecimento comunicacional conceitos. CD- Rom. São Paulo: Sociedade Brasileira de Estudos Interdisciplinares da Comunicação, 2010, p. 312-313.

HALBWACHS, Maurice. A memória coletiva. 2. ed. São Paulo: Centauro, 2013.

HOGGART, Richard. As utilizações da cultura. V. 1. Lisboa: Presença, 1987a.

HOGGART, Richard. As utilizações da cultura. V. 2. Lisboa: Presença, 1987b.

KANTAR IBOPE MEDIA. Book de rádio. 4. ed. 2017. Disponível em: <https://www.kantaribopemedia.com/book-de-radio-4a-edicao/>. Acesso em: 15 maio 2018.

LAVILLE, Christian; DIONNE, Jean. A construção do saber: manual de metodologia da pesquisa em ciências humanas. Porto Alegre: Artmed; Belo Horizonte: Editora UFMG, 1999.

MCLUHAN, Marshall. Os meios de comunicação como extensões do homem. São Paulo: Cultrix, 2000.

POLLAK, Michael. Memória e identidade social. Estudos Históricos, Rio de Janeiro, v. 5, n. 10, p. 200-2015, jul./dez. 1992.

SILVERSTONE, Roger. Por que estudar a mídia? São Paulo: Loyola, 2002.

Submetido em: 23.04.2018

Aprovado em: 23.06.2018 